\title{
Decision Making Methodology for Heat Sink Material Selection Using a Compromise Ranking and Outranking Method under Fuzzy Environment
}

\author{
${ }^{1}$ Arulmurugan L, ${ }^{2}$ Dr.llangkumaran M \\ ${ }^{1}$ Assistant Professor, Department of Mechatronics Engineering,K S Rangasamy College of Technology, \\ Tiruchengode, India. \\ E-mail ID: arulmurugan83@gmail.com \\ ${ }^{2}$ Professor and Head, Department of Mechatronics Engineering, K S Rangasamy College of Technology, \\ Tiruchengode, India. \\ E-mail ID: maniilankumaran@gmail.com
}

\begin{abstract}
This paper proposes judicious selection of heat sink materials by extensive evaluation under consideration of numerous alternative materials and evaluation criteria. This enhances the reliability and life of modern electronic devices. Thermal management of electronic devices relies on stabilizing the component temperature at an acceptable level. A hierarchical decision making framework structure based on novel hybrid fuzzy set theory combined with multi-criteria decision-making (MCDM) model is formed. A fuzzy analytic hierarchical process (FAHP) is more realistic to use linguistic terms to describe the expectation value, perception value and important weight of evaluation criteria. This study comprises six alternatives and seven criteria such as thermal conductivity, density, specific heat, melting point, latent heat of fusion, thermal expansion and cost. The results obtained from FAHP-TOPSIS and FAHP- VIKOR is compared with each other. These results help the designer to choose the apt heat sink material for designing and developing electronic packages.
\end{abstract}

\section{Indexing terms/Keywords}

Multi criteria decision making, Heat sink, Thermal management system, Electronic devices, Fuzzy set theory.

\section{INTRODUCTION}

Electronic manufacturing industries are facing problems in thermal management of electronic equipment due to the increase in heat dissipation. The heat must be dissipated to prevent the deterioration of performance, improving the long term consistency and safety of the components. In attempt to enhance the performance of thermal management, numerous study and investigation have been conducted and various methods have been proposed to reduce the thermal impact on the performance of the electronic device. Virtually all of the heat generated in the electronic device is removed by the heat sink. The manufacturing industries are constantly striving to find low cost, lighter and more thermal conductive material to make efficient heat sinks. The heat sink material selection involves a systematic approach for seeking the best match between the design requirements and the materials attributes. The material selection problems with noncommensurable and conflicting criteria can be resolved by MCDM methods, since they are used for solving conflicting ideas with multiple criteria. The MCDM combined with fuzzy set theory has been used to interpret the linguistic information in accordance with the subjective evaluation and represent the uncertainty in human perceptions involved in heat sink material selection problem in electronic manufacturing industry. The aim of this article is to deal with the selection of suitable heat sink material for thermal management of electronics cooling applications in manufacturing industry.

\section{LITERATURE REVIEW}

In this section, the significance of heat sink material in thermal management system, evolution of material and MCDM are reviewed.

\subsection{Literature review on Heat sink}

Micro-channel heat sinks constitute an innovative cooling technology for the removal of a large amount of heat from a small area [1]. Any material can act as a heat sink by increasing its temperature whilst storing thermal energy as sensible heat. However, technical constraints often determine maximum temperatures or mass due to functional and safety requirements limit the amount of sensible heat that can be stored [2]. Research in the field of heat transfer enhancement is still ongoing. Forced convection cooling may become a necessary part of the thermal management of future handheld devices to accommodate increased power dissipation levels [3]; it is one of the most decisive methods of transferring heat from electronic products because it is low-cost, easily implemented, and highly efficient. A common method of increasing heat transfer from an electronic component is to attach a heat sink to it. The heat that is generated by the electronic component is conducted to the heat sink, from which it is transferred out of the system by convection. A proper tuning of heat sink configuration is an effective way to improve the convective air stream over the heat sink surface and subsequently produce significant improvement in heat sink thermal performance [4]. The use of active thermal methods such as miniature centrifugal fans proved to be inefficient due to space, noise levels, high maintenance and additional power consumption [3]. A number of factors used for cooling methodology includes: space, operating environment, heat dissipated, cost of materials and maintenance required [5]. Chen [6] has investigated the heat dissipation performance of the pin-fin heat sinks under uncertainties. Among the various types of cooling systems that have been developed, the plate-fin heat sink is the most widely used because of its simple design and ease of fabrication [7]. Fiedler [8] investigated the energy storage capacity and transient thermal behavior of compact heat sinks enclosed in aluminum cases. Heat sinks contained different cores that improve thermal conduction and/or energy storage capacity. 


\subsection{Literature review on integrated MCDM methods}

The compromise ranking and outranking methods are computationally easy to implement and sounds logical, as it helps the decision maker to choose the best industrial robot from a finite set of alternate robots [2]. Fuzzy sets extend deterministic multi-criteria decision-making methods to deal with uncertainty and imprecision in decision-making [9]. Opricovic and Tzeng [10] have compared the two MCDM methods, VIKOR and TOPSIS by focusing on modeling aggregating function and normalization, in order to reveal and compare the procedural basis of these two MCDM methods. Dagdeviren et al. [11] proposed the systematic evaluation model for the weapon selection process in defense industries to select an optimal weapon among a set of available alternatives with integrated AHP and TOPSIS method under fuzzy environment. Sun [12] has proposed a model to evaluate the performance of global top four notebook computer ODM companies. This study integrated two MCDM methods namely AHP and TOPSIS under fuzzy environment. Chu et al., [13] proposed three MCDM methods, simple average weight TOPSIS and VIKOR to establish objective and measurable patterns to obtain anticipated achievements of knowledge communities through a group-decision comparison. They discovered that TOPSIS and VIKOR methods can be used to highlight innovative idea, academic analysis, and practical appliance value. Sen Liu [14] proposes a multi-attribute group decision-making based scientific decision tool to help firms to judge which cloud computing vendor is more suitable for their need by considering more comprehensive influence factors. Rao [15] applied the improved compromise ranking method to select the apt material for engineering applications. Ang and Tien-Chang [16] proposed a fuzzy MCDM approach to selecting the best-suited tool steel material for specific manufacturing applications such as die design, and jig and fixture design. Material selection is one of the most important activities in the design process.

\subsection{Research gap}

Based on literature review, several researchers have been done in integrated MCDM methods for numerous applications. But the usage of these integrated MCDM in the selection of heat sink is found inadequate. This article focuses on the development and application of MCDM in heat sink material selection and design challenges providing designer with broader and more versatile tool to optimize device cost, performance and reliability. One of the most challenging problems in real life manufacturing environment is faced in the selection of heat sink material for electronic cooling application. Due to the impressive increase of the power dissipation many engineers do not consider heat sink material to be a feasible solution for the far future of thermal management. Selection of heat sink material involves complex decision variables. This method solves problem in a fuzzy environment since both criteria and weights are vague in nature. Furthermore, vagueness also exists in determining how each criterion impacts the attributes for evaluation. In order to deal with vagueness and uncertainty associated with decision making problem, fuzzy based methods are being used in the present study.

\section{Methodology}

The following briefly describes several MCDM methods, including fuzzy analytical hierarchy process (FAHP) with VIKOR and TOPSIS.

\subsection{FAHP method}

In AHP method proposed by Saaty [17], the decision problem is structured hierarchically at different levels with each level consisting of a finite number of elements [18]. Laarhoven and Pedrycz [19] applied fuzzy logic principle. The procedural steps involved in FAHP method are listed below:

Step 1: With the FAHP, the complex MCDM problems are fragmented and arranged in a hierarchical structure similar to a family tree with at least three levels: overall goal of the problem at the top, multi criteria that define criteria in the middle and decision criteria at the bottom.

Step 2: The pair-wise comparison matrix $A$ is fuzzified using the triangular fuzzy number (TFN) $M=(I, m, u)$, where $I$ and $u$ represent lower and upper bound range, respectively, that might exist in the preferences expressed by the decisionmaker. The membership functions of the TFN i.e. $M_{1}, M_{3}, M_{5}, M_{7}$, and $M_{9}$ are used to represent the assessment from equally preferred $\left(M_{1}\right)$, moderately preferred $\left(M_{3}\right)$, strongly preferred $\left(M_{5}\right)$, very strongly preferred $\left(M_{7}\right)$, and extremely preferred $\left(M_{9}\right)$. This project uses a TFN to express the membership functions of the aforementioned expression values on five scales used for FAHP listed in Table 1.

Table 1: Membership function of Fuzzy numbers

\begin{tabular}{|l|l|l|l|}
\hline Linguistic scale for importance & Fuzzy number & $\begin{array}{l}\text { TFN } \\
(L, M, U)\end{array}$ & Reciprocal of TFN $(1 / U, 1 / M, 1 / L)$ \\
\hline Just equal & & $(1,1,1)$ & $(1,1,1)$ \\
\hline Equal importance & $M_{1}$ & $(1,1,3)$ & $(0.33,1,1)$ \\
\hline Weak importance of one over another & $M_{3}$ & $(1,3,5)$ & $(0.2,0.33,1)$ \\
\hline Essential or strong importance & $M_{5}$ & $(3,5,7)$ & $(0.14,0.2,0.33)$ \\
\hline Very strong importance & $M_{7}$ & $(5,7,9)$ & $(0.11,0.14,0.2)$ \\
\hline Extremely preferred & $M_{9}$ & $(7,9,9)$ & $(0.11,0.11,0.14)$ \\
\hline
\end{tabular}

4565 | P a g e 
Let $C=\left\{C_{j j} j=1,2_{z \ldots \ldots} \ldots \ldots\right\}$ be a set of criteria. The result of the pair-wise comparison on " $n$ " criteria can be summarized in an $(n \times n)$ evaluation matrix $A$ in which every element $a_{i j}\left(i j=1_{x} 2_{n \ldots \ldots} n\right)$ is the quotient of weights of the criteria, as

$$
A=\left[\begin{array}{cccc}
a_{11} & a_{12} & \cdots & a_{1 n} \\
a_{21} & a_{22} & \cdots & a_{2 n} \\
\vdots & \vdots & \cdots & \vdots \\
a_{n 1} & a_{n 2} & \cdots & a_{n n}
\end{array}\right], a_{i i}=1, a_{j i}=\frac{1}{a_{1 j}}, a_{i j} \neq 0 .
$$

Step 3: The mathematical process is used to normalize and find the relative weights of each matrix. The relative weights are given by the right Eigen vector $(\mathrm{W})$ corresponding to the largest Eigen value $\left(\lambda_{\max }\right)$, as

$$
A_{W}=\lambda_{\max } W
$$

It should be noted that the quality of output of FAHP is strictly related to the consistence of the pair-wise comparison judgments. The consistency is defined by the relation between the entries of $A: a_{i j} \times a_{j k}=a_{i k}$. The consistency index $(\mathrm{Cl})$ is

$$
\mathrm{Cl}=\left(\lambda_{\max }-\mathrm{n}\right) /(\mathrm{n}-1)
$$

Step 4: The pair-wise comparison is normalized and priority vector is computed to weigh the elements of the matrix. The values in this vector sum to 1 . The consistency of the subjective input in the pair-wise comparison matrix can be determined by calculating a consistency ratio (CR). In general, a CR having a value less than 0.1 is considered to be good [17]. The $\mathrm{CR}$ for each square matrix is obtained from dividing $\mathrm{Cl}$ values by the random consistency index $(\mathrm{RCl})$ values.

$$
\mathrm{CR}=\mathrm{Cl} / \mathrm{RCl}
$$

The $\mathrm{RCl}$ which is obtained from a large number of simulations runs and varies depending on the order of the matrix. Table 2 lists the values of the $\mathrm{RCl}$ for matrices of order 1 - 10 obtained by approximating random indices using a sample size of 500. The acceptable CR range varies according to the size of the matrix, that is, 0.05 for a $3 \times 3$ matrix, 0.08 for a $4 \times 4$ matrix and 0.1 for all larger matrices having $n \geq 5$. If the value of $C R$ is equal to or less than that value, it implies that the evaluation within the matrix is acceptable or indicates a good level of consistency in the comparative judgments represented in that matrix. In contrast, if the value of CR is more than the accepted value, it indicates that inconsistency of judgments within that matrix has occurred and the evaluation process should therefore be reviewed, reconsidered, and improved.

Table 2: Random Consistency Index (RCl)

\begin{tabular}{|c|c|c|c|c|c|c|c|c|c|c|}
\hline No & 1 & 2 & 3 & 4 & 5 & 6 & 7 & 8 & 9 & 10 \\
\hline $\mathrm{RCl}$ & 0 & 0 & 0.52 & 0.89 & 1.11 & 1.25 & 1.35 & 1.40 & 1.45 & 1.49 \\
\hline
\end{tabular}

\subsection{TOPSIS method}

The TOPSIS was first developed by Hwang and Yoon [20]. It is a relatively simple, fast and a systematic procedure [21]. The procedure of TOPSIS method is as follows:

- Step 1: Normalization of the evaluation matrix: The process is used to transform different scales and units among various criteria into common measurable units to allow comparisons across the criteria. Assume $f_{i j}$ to be of the evaluation matrix $R$ of alternative $j$ under evaluation criterion $i$ then an element $r_{i j}$ of the normalized evaluation matrix $R$ can be calculated by many normalization methods to achieve this objective.

$$
r_{\mathrm{i} j}=\frac{f_{\mathrm{iff}}}{\sqrt{\sum_{j-1}^{j} f_{i j}^{2}}} \quad j=1,2,3 \ldots, j \quad, \quad i=1,2,3 \ldots, n .
$$

- $\quad$ Step 2: Construction of the weighted normalized decision matrix: The weighted normalized decision matrix can be calculated by multiplying the normalized evaluation matrix $r_{i j}$ with its associated weight $w_{i}$ to obtain the result

$$
V_{i j}=w_{i j}^{*} r_{i j} \quad j=1,2 \ldots j, \quad i=1,2,3 \ldots n .
$$

Where $w_{i}$ is given by $\sum_{i-1}^{n} w_{i}=1$ 
- $\quad$ Step 3: Determination of the positive-and negative-ideal solutions: The positive-ideal solution $A^{*}$ indicates the most preferable alternative and the negative-ideal solution $A^{-}$indicate the least preferable alternative.

$$
\begin{aligned}
& A^{*}=\left\{v_{1, \ldots \ldots \ldots}^{*} v_{i}^{*}\right\}=\left\{\left(\max _{j} v_{i j} \mid i \in I^{n}\right),\left(\min _{j} v_{i j} \mid i \in I\right)\right\} \\
& A^{-}=\left\{v_{1, \ldots \ldots \ldots}^{-} v_{i}\right\}=\left\{\left(\min _{j} v_{i j} \mid i \in I^{\prime}\right),\left(\max _{j} v_{i j} \mid i \in I\right)\right\}
\end{aligned}
$$

- $\quad$ Step 4: Calculation of the separation measure: The separation from the positive- and negative-ideal solutions for each alternative can be measured by the $n$-criteria Euclidean distance.

$$
\begin{aligned}
& \mathrm{D}_{\mathrm{j}}^{*}=\sqrt{\sum_{\mathrm{i}=1}^{\mathrm{n}}\left(\mathrm{v}_{\mathrm{i}_{1}}-\mathrm{v}_{\mathrm{i}}^{*}\right)^{2}}, \quad \mathrm{j}=1,2,3 \ldots j . \\
& D_{j}^{-}=\sqrt{\sum_{i=1}^{n}\left(v_{i_{1}}-v_{i}^{-}\right)^{2}}, j=1,2,3 \ldots j
\end{aligned}
$$

- $\quad$ Step 5: Calculation of the relative closeness to the ideal solution: The relative closeness of the $i^{\text {th }}$ alternative with respect to ideal solution $\mathrm{A}^{+}$is defined as follows:

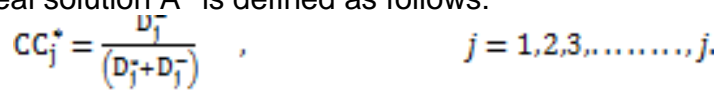

- Step 6: Ranking the priority: A set of alternatives then can be preference ranked according to the descending order of $C C_{j}^{*}$.

\subsection{VIKOR method}

The VIKOR method was developed for multi-criteria optimization of complex problems. This method focuses on ranking and selecting from a set of alternatives and determines the compromise solution obtained with the initial weights for a problem with conflicting criteria. Assuming that each alternative is computed according to each criterion function, the compromise ranking is performed by comparing the measure of closeness to the ideal alternative. The various alternatives are denoted as $A_{1}, A_{2} \ldots . A_{m}$. For alternative $A_{j}$, the rating of the $i^{\text {th }}$ aspect is denoted by $f_{i j}$, that is, $f_{i j}$ is the value of $i^{\text {th }}$ criterion function for the alternative $a_{j} ; n$ is the number of criteria. Development of VIKOR is started with the following form of $L_{P}$ - metric:

$$
\left.L_{p j}=\left\{\sum_{i=1}^{n}\left[W_{i}\left(f_{i}^{*}-f_{i j}\right) /\left(f_{i}^{*}-f_{i}^{-}\right)\right]^{p}\right\}^{1 / p} \quad 1 \leq p \leq \infty_{v j}=1_{s} 2_{s a n}\right]
$$

In VIKOR method $L_{1, j}$ (as $S_{j}$ ) and $L_{\infty, j}\left(\right.$ as $\left.R_{j}\right)$ are used to formulate ranking measure. The results are obtained by min $S_{j}$ is with the maximum group utility ("majority" rule), and the answer obtained by $\operatorname{minR}_{\mathrm{j}}$ is with a minimum individual regret of the "opponent". The compromise ranking algorithm of VIKOR encompasses the following steps:

- Step 1: The purpose of normalizing the performance metrics is to unify the unit of matrix entries. The determination of normalized values of alternatives $x_{i j}$ is the numerical score of alternative $\tilde{j}$ on criterion $\bar{i}$. The corresponding normalized value $f_{i j}$ is defined as follows:

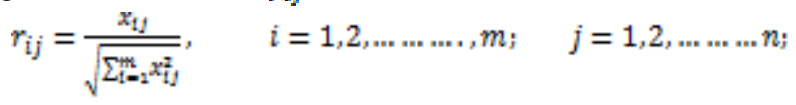

- Step 2: Determine the best $f_{i}^{*}$ and the worst $f_{i}^{-}$values for each criterion functions, $i=1{ }_{x} 2_{x a x} x_{x \times s} m$

$$
f_{i}^{*}=\max _{j} f_{i j^{s}} \quad f_{i}^{-}=\min _{j} f_{i j}
$$

- $\quad$ Step 3: The utility measure and the regret measure for each maintenance alternative are given as:

$$
\begin{aligned}
& S_{j}=\frac{\sum_{i=1}^{N} w_{i}\left(f_{i}^{*}-f_{i j}\right)}{f_{i}^{N}-f_{i}^{-}} \\
& R_{j}=\left[\frac{w_{i}\left(f_{i}^{*}-f_{i j}\right)}{f_{i}^{*}-f_{i}^{-}}\right]
\end{aligned}
$$

Where $S_{j}$ and $R_{j}$ represent the utility measure and the regret measure, respectively and $w_{j}$ the weight of the $\mathrm{j}^{\mathrm{th}}$ criterion.

- $\quad$ Step 4: Calculate the VIKOR index

$$
Q_{j}=\frac{v\left(s_{j}-s^{2}\right)}{s^{2}-s^{2}}+\frac{(1-v)\left(R_{j}-R^{2}\right)}{R^{2}-R^{2}}
$$

Where, $s^{*}=\min _{j} S_{j}, S^{-}=\max _{j} S_{j}, R^{*}=\min _{j} R_{j}, R^{-}=\max _{j} R_{j}$ and $v$ is introduced as weight of the strategy of "the majority of criteria" (or "the maximum group utility"), here $v=0.5$.

- Step 5: Rank the order of preference.

The alternate with the smallest VIKOR value is determined to be the best solution. Proposed a compromise solution with an alternative ' $A$ ', , which is ranked the best by the measuring $Q$ (minimum) if the following two conditions are satisfied: 


$$
Q\left(A^{x i}\right)-Q\left(A^{x}\right) \geq D Q
$$

Where $A^{n s}$ is the alternative with second position in the ranking list by $Q ; D Q=1 /(m-1)$, and $m$ the number of alternatives.

$>$ C2. Acceptable stability in decision-making:

Alternative $A^{B}$ must be the best ranked by $\mathrm{S}$ or $\mathrm{R}$ or both. This compromise solution is stable within a decision-making process, which could be "voting by majority rule" (when $v>0.5$ is needed), or "by consensus" v $\approx 0.5$, or "with veto" ( $v<$ $0.5)$. Here, $v$ is the weight of the decision-making strategy "the majority of criteria" (or "the maximum group utility"). If one of the conditions is not satisfied, then a set of compromise solutions is proposed, which consists of the following:

- Alternatives $A^{b}$ and $A^{t s}$ if only condition $\mathrm{C} 2$ is not satisfied, or

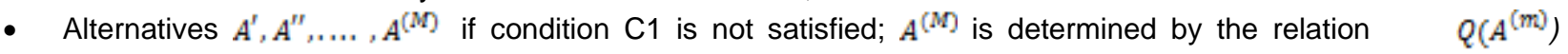
$-Q(A)<D Q$ for maximum $M$ (the positions of these alternatives are "in closeness").

\subsection{Fuzzy set theory}

A fuzzy set is a class of objects with grades of membership. It is characterized by a membership function that assigns a grade of membership ranging between 0 and 1 for each object of the class. It can solve real-world problems by providing a wider frame than classic set theory. Zadeh [22] proposed the fuzzy set theory for scientific environment and later it was made available to other fields as well. In our daily life, there are different decision-making problems of diverse intensity, and if the fuzziness of human decision-making is not taken into account, the results can be misleading. Fuzzy decisionmaking turned out to be a rational approach in handling decision-making that takes into account of human subjectivity. Bellman and Zadeh [23] described the decision making methods in fuzzy environments. The use of fuzzy set theory allows the decision-makers to incorporate uncertain information into decision models [24]. The fuzzy set theory resembles human reasoning with the use of approximate information and certainty to generate decisions and it's a better approach to convert linguistic variables to fuzzy numbers under ambiguous assessments. The fuzzy set theory, which is incorporated with AHP, allows us to have a more accurate description of the decision-making process.

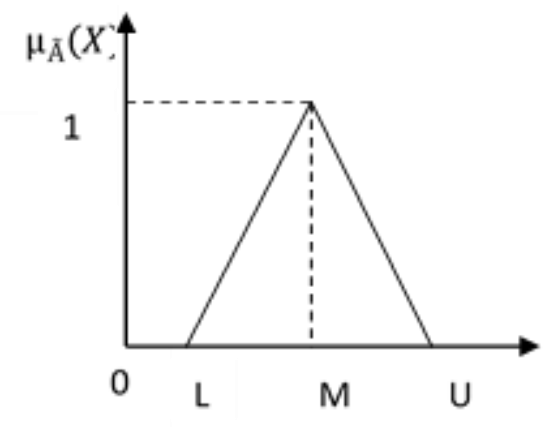

Fig 1: Triangular fuzzy numbers

The uncertain comparison ratios are expressed as fuzzy numbers. It is possible to use different fuzzy numbers according to the situation. In general, triangular and trapezoidal fuzzy numbers are used. In common practice, the triangular form of the membership function is used most often $[25,26]$. The reason for using a TFN is to be intuitively easy for the decisionmakers to use and calculate. In addition, modeling using TFN has proved to be an effective way for formulating decision problems where the information available is subjective and imprecise $[27,28]$. The evaluation criterion in the judgment matrix and weight vector is represented by TFNs. A fuzzy number is a special fuzzy set $F=\left\{\left(x, \mu F(x)_{x} x \in \mathrm{R}_{\}}\right.\right.$where $\mathrm{x}$ takes its value on the real line $R_{1}:-\infty<x<+\infty$ and $\mu F(x)$ is a continuous mapping from $\mathrm{R}_{1}$ to the close interval $[0,1]$. A TFN can be denoted as $M=(\mathrm{l}, \mathrm{m}$, and $\mathrm{u})$ and can be represented as follows:

$$
\mu_{A}(X)=\left\{\begin{array}{lr}
0_{s} & x_{s} l_{s} \\
\frac{(x-D)}{(m-1)^{s}} & l \leq x \leq m_{x} \\
\frac{(u-x)}{(u-m)^{s}} & m \leq x \leq u_{x} \\
0, & x>u
\end{array}\right.
$$

According to the nature of TFN, it can be defined as a triplet (I, $\mathrm{m}, \mathrm{u})$. The TFN can be represented as follows: $\tilde{\mathrm{A}}=\left(L_{x} M_{x} U\right)$ where $L$ and $U$ represent the fuzzy probability between the lower and upper boundaries of evaluation. The TFN is shown in Figure. 1.

The two fuzzy numbers $\tilde{\mathrm{A}}_{1}=\left(L_{1}, M_{1}, U_{1}\right)$ and $\tilde{\mathrm{A}}_{2}=\left(L_{2}, M_{2}, U_{2}\right)$ are assumed.

$$
\begin{aligned}
& \tilde{\mathrm{A}}_{1} \oplus \tilde{\mathrm{A}}_{2}=\left(L_{1}, M_{1}, U_{1}\right) \oplus\left(L_{2}, M_{2}, U_{2}\right)=\left(L_{1}+L_{2}, M_{1}+M_{2}, U_{1}+U_{2}\right) \\
& \tilde{A}_{1} \otimes \tilde{A}_{2}=\left(L_{1}, M_{1}, U_{1}\right) \otimes\left(L_{2}, M_{2}, U_{2}\right)=\left(L_{1} L_{2}, M_{1} M_{2}, U_{1} U_{2}\right)
\end{aligned}
$$




$$
\begin{aligned}
& \tilde{A}_{1}-\tilde{A}_{2}=\left(L_{1}, M_{1}, U_{1}\right)-\left(L_{2}, M_{2}, U_{2}\right)=\left(L_{1}-L_{2}, M_{1}-M_{2}, U_{1}-U_{2}\right) \\
& \tilde{A}_{1} \div \tilde{A}_{2}=\left(L_{1}, M_{1}, U_{1}\right) \div\left(L_{2}, M_{2}, U_{2}\right)=\left(L_{1} / L_{2}, M_{1} / M_{2}, U_{1} / U_{2}\right) \\
& O P_{v}, Z Z A_{1} \tilde{A}_{1}^{-1}=\left(L_{1}, M_{1}, U_{1}\right)^{-1}=\left(1 / L_{1}, 1 / M_{1}, 1 / U_{1}\right)
\end{aligned}
$$

\section{Proposed Methodology}

The Fuzzy AHP is used to determine the preference weights of evaluation. Compromise Ranking and Outranking Method is used to improve the gaps between alternatives and conflicting criteria to evaluate the apt material for cooling application.

\subsection{Criteria for selecting an optimum material}

The following criteria are used for selecting heat sink materials.

- Thermal conductivity: It helps in sorting out the best material for manufacturing heat sink. It's a bulk property that describes the ability of a material to transfer heat and it plays a significant role in the cooling of electronics equipment.

- Density: The substance is the relationship between the mass of the substance and how much volume it takes up.

- Specific heat capacity: The material is the heat required to raise unit mass of substance by one degree of temperature.

- Melting point: Melting point of a solid is the temperature at which it changes state from solid to liquid at atmospheric pressure. Fusion or solidification is the heat absorbed when a substance changes its phase from liquid to solid.

- Thermal Expansion: It is the tendency of matter to change in shape, area, and volume in response to a change in temperature through heat transfer.

- $\quad$ Cost: imprecise cost

\subsection{FAHP computations}

The decision hierarchy diagram is established using identified evaluation criteria and the alternate materials are shown in Figure 2.

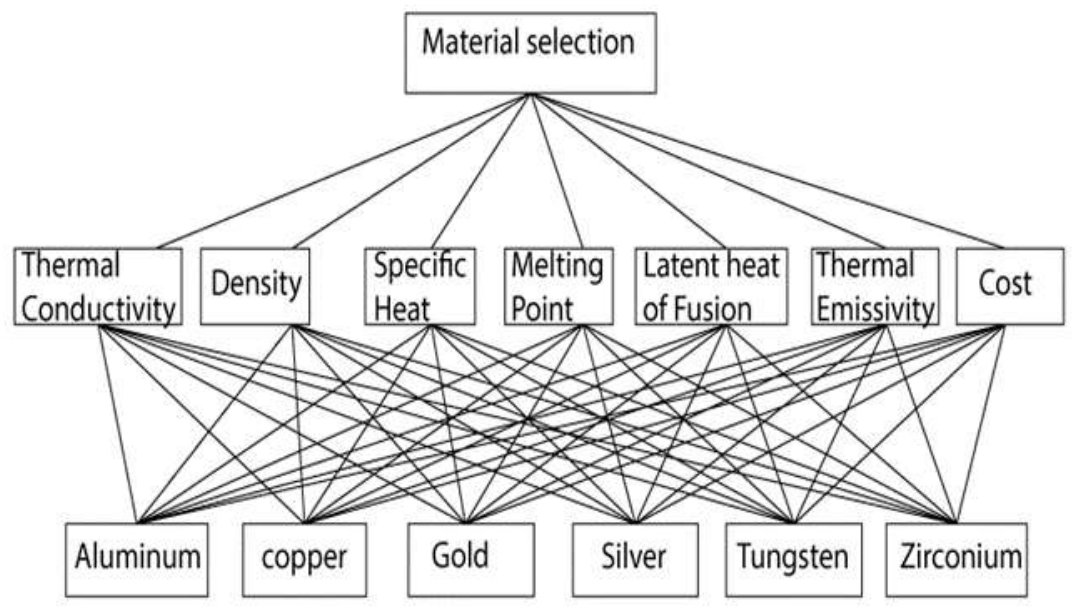

Fig 2: Decision hierarchy of Heat Sink material selection

There are three levels in the decision hierarchy structure of the heat sink material selection process. The selection of optimal available material at the first level, the criteria are at the second level and discover the alternate materials are at the third level of the hierarchy. The weights of the criteria are computed using FAHP method. The relative weights are determined using pair wise comparison of the criteria. Using satty's scale each criterion is compared with other criteria. The fuzzy comparison judgments of the seven criteria with respect to overall objective are shown in Table 3 . The geometric mean of the values obtained from the evaluations is computed. A consensus is arrived at on a final pair-wise comparison matrix formed. On the basis of this final comparison matrix, the weights of the criteria are calculated. Then $\mathrm{Cl}$ and $\mathrm{CR}$ are calculated to check whether the importance given to the criteria in the pair-wise comparison matrix is correct. The weights are approved by a decision-making team towards the completion of this phase. The obtained relative weights, $\mathrm{Cl}$, and $\mathrm{CR}$ of criteria are given in Table 4. 
Table 3: Pairwise comparison matrix of criteria

\begin{tabular}{|c|c|c|c|c|c|c|c|}
\hline & $\begin{array}{c}\text { Thermal } \\
\text { Conductivity } \\
\text { Btu / (hr-ft-F) }\end{array}$ & $\begin{array}{c}\text { Density } \\
\text { (lbs/in) }\end{array}$ & $\begin{array}{c}\text { Specific Heat } \\
(\text { Btu/lb/F) }\end{array}$ & $\begin{array}{c}\text { Melting } \\
\text { Point (F) }\end{array}$ & $\begin{array}{c}\text { Latent Heat } \\
\text { of Fusion } \\
(\mathrm{Btu} / \mathrm{lb})\end{array}$ & $\begin{array}{c}\text { Thermal } \\
\text { Expansion (in/in/F } \\
\left.\times 10^{-6}\right)\end{array}$ & $\begin{array}{c}\text { Cost } \\
/ \mathrm{kg}\end{array}$ \\
\hline $\begin{array}{c}\text { Thermal } \\
\text { Conductivity }\end{array}$ & $1,1,1$ & $5,7,9$ & $5,7,9$ & $5,7,9$ & $3,5,7$ & $0.2,0.33,1$ \\
\hline Density & $0.2,0.14,0.11$ & $1,1,3$ & $0.2,0.33,1$ & $1,3,5$ & $0.2,0.33,1$ & $0.14,0.2,0.33$ & $0.11,0.11,0.14$ \\
\hline Specific Heat & $0.2,0.14,0.11$ & $5,3,1$ & $1,1,3$ & $1,3,5$ & $0.2,0.33,1$ & $0.14,0.2,0.33$ & $0.11,0.11,0.14$ \\
\hline Melting Point & $0.2,0.14,0.2$ & $1,0.33,0.2$ & $1,0.33,0.2$ & $1,1,3$ & $0.2,0.33,1$ & $0.11,0.14,0.2$ & $0.11,0.11,0.14$ \\
\hline $\begin{array}{c}\text { Latent Heat of } \\
\text { Fusion }\end{array}$ & $0.33,0.12,0.14$ & $5,3,1$ & $5,3,1$ & $5,3,1$ & $1,1,3$ & $0.2,0.33,1$ & $0.11,0.14,0.2$ \\
\hline $\begin{array}{c}\text { Thermal } \\
\text { Expansion }\end{array}$ & $1,0.33,0.2$ & $7,5,3$ & $7,5,3$ & $9,7,5$ & $5,3,1$ & $1,1,3$ \\
\hline Cost & $5,3,1$ & $9,9,7$ & $9,9,7$ & $9,9,7$ & $9,7,5$ & $0.14,0.2,0.33$ \\
\hline
\end{tabular}

Table 4: Results obtained with FAHP

\begin{tabular}{|c|c|c|c|}
\hline Criteria & Weights & $\lambda_{\max }, \mathbf{C l}, \mathbf{R C l}$ & CR \\
\hline Thermal Conductivity & 0.253 & \multirow{7}{*}{$\begin{array}{c}\lambda_{\text {max }}=7.577 \\
\mathrm{Cl}=0.096\end{array}$} & \multirow{7}{*}{0.071} \\
\hline Density & 0.038 & & \\
\hline Specific Heat & 0.046 & & \\
\hline Melting Point & 0.027 & & \\
\hline Latent Heat of Fusion & 0.071 & & \\
\hline Thermal Expansion & 0.149 & & \\
\hline Cost & 0.416 & & \\
\hline
\end{tabular}

\subsection{TOPSIS computations}

In TOPSIS method normalized values obtained using Eq. 5 is given in Table 5. The data are obtained based on many experiments with the use of trial and error methods. The normalized data are given in Table 6 . The FAHP criteria weights are considered to compute the weighted normalized decision matrix using Eq. 6 and the data is given in Table 6 . The positive- and negative-ideal solutions are calculated using Eq. 7 and 8 and are given in Table 7. The separation measures of each alternative are computed using Eq. 9 and 10.And these are given in Table 8. The calculation of the relative closeness to the ideal solution is carried out using Eq. 11 and given in Table 8. Finally, according to the relative closeness to the ideal solution value, the ranks are preferred to the materials and the obtained results are given in Table 8 .

Table 5: Material Properties

\begin{tabular}{|l|c|c|c|c|c|c|c|}
\hline Material & $\begin{array}{c}\text { Thermal } \\
\text { Conductivity } \\
\text { Btu / (hr-ft-F) }\end{array}$ & $\begin{array}{c}\text { Density } \\
(\mathbf{I b s} / \mathbf{i n})\end{array}$ & $\begin{array}{c}\text { Specific } \\
\text { Heat } \\
(\mathbf{B t u} / \mathbf{l b} / \mathbf{F})\end{array}$ & $\begin{array}{c}\text { Melting Point } \\
\mathbf{( F )}\end{array}$ & $\begin{array}{c}\text { Latent Heat of } \\
\text { Fusion } \\
\text { (Btu/lb) }\end{array}$ & $\begin{array}{c}\text { Thermal } \\
\text { Expansion } \\
\text { (in/in/F } \mathbf{i n} \\
\mathbf{1 0}\end{array}$ & $\begin{array}{c}\text { Cost } \\
\text { / kg }\end{array}$ \\
\hline Aluminum & 136 & 0.098 & 0.24 & 1220 & 169 & 13.1 & 118 \\
\hline Copper & 231 & 0.322 & 0.095 & 1976 & 91.1 & 9.8 & 413 \\
\hline Gold & 183 & 0.698 & 0.032 & 1945 & 29 & 7.9 & 266560 \\
\hline Silver & 247.87 & 0.379 & 0.057 & 1760 & 38 & 10.8 & 45380 \\
\hline Tungsten & 100.53 & 0.697 & 0.04 & 6170 & 79 & 2.5 & 2576 \\
\hline Zirconium & 145 & 0.234 & 0.067 & 3350 & 108 & 3.2 & 9039 \\
\hline
\end{tabular}


Table 6: Normalized decision matrix (ND) And Weighted normalized decision matrix (WN)

\begin{tabular}{|c|c|c|c|c|c|c|c|c|c|c|c|c|c|c|}
\hline \multirow[t]{2}{*}{$M$} & \multicolumn{2}{|c|}{$\begin{array}{c}\text { Thermal } \\
\text { Conductivity }\end{array}$} & \multicolumn{2}{|c|}{ Density } & \multicolumn{2}{|c|}{ Specific Heat } & \multicolumn{2}{|c|}{ Melting Point } & \multicolumn{2}{|c|}{$\begin{array}{l}\text { Latent Heat } \\
\text { Fusion }\end{array}$} & \multicolumn{2}{|c|}{$\begin{array}{l}\text { Thermal } \\
\text { Expansion }\end{array}$} & \multicolumn{2}{|c|}{ Cost / kg } \\
\hline & ND & WN & ND & WN & ND & WN & ND & WN & ND & WN & ND & WN & WN & ND \\
\hline Al & 0.30 & 0.07 & 0.08 & 0.00 & 0.86 & 0.04 & 0.15 & 0.01 & 0.70 & 0.05 & 0.60 & 0.09 & 0.01 & 0.01 \\
\hline $\mathrm{Cu}$ & 0.51 & 0.13 & 0.28 & 0.01 & 0.34 & 0.01 & 0.25 & 0.01 & 0.38 & 0.02 & 0.45 & 0.06 & 0.15 & 0.06 \\
\hline $\mathrm{Au}$ & 0.41 & 0.10 & 0.61 & 0.02 & 0.11 & 0.01 & 0.24 & 0.01 & 0.12 & 0.08 & 0.36 & 0.05 & 0.98 & 0.98 \\
\hline $\mathrm{Ag}$ & 0.55 & 0.14 & 0.33 & 0.01 & 0.20 & 0.01 & 0.22 & 0.01 & 0.15 & 0.01 & 0.50 & 0.07 & 0.16 & 0.97 \\
\hline w & 0.22 & 0.05 & 0.61 & 0.02 & 0.14 & 0.01 & 0.78 & 0.02 & 0.33 & 0.03 & 0.11 & 0.01 & 0.95 & 0.39 \\
\hline $\mathrm{Zr}$ & 0.32 & 0.08 & 0.20 & 0.00 & 0.24 & 0.01 & 0.42 & 0.01 & 0.45 & 0.03 & 0.14 & 0.02 & 0.34 & 0.38 \\
\hline
\end{tabular}

\subsection{VIKOR computations}

The VIKOR methodology is also used for selecting heat sink materials. The normalized decision matrix is calculated same as TOPSIS methodology; the resulting normalized decision matrix is shown in Table 6. The best and worst values of the each criterion are calculated by using Eq. 14 and the obtained values are given in Table 7. The values of utility measure and regret measure are calculated using the Eq. 15 and 16 are given in Table 8. Finally, the VIKOR index value is calculated using an Eqn. 17 and are given in Table 8. On the basis of VIKOR index value the ranks are assigned to the materials and the obtained results are presented in Table 8.

Table 7: Positive ideal solution $\left(A^{\star}\right)$ and Negative ideal solution ( $\left.A-\right)$ of TOPSIS and best value and worst value for VIKOR

\begin{tabular}{|l|c|c|c|c|}
\hline \multirow{2}{*}{\multicolumn{1}{|c|}{ Criteria }} & \multicolumn{2}{c|}{ TOPSIS } & \multicolumn{2}{c|}{ VIKOR } \\
\cline { 2 - 5 } & $\begin{array}{c}\text { Positive ideal } \\
\text { solution A }\end{array}$ & $\begin{array}{c}\text { Negative ideal } \\
\text { solution A }\end{array}$ & $\tilde{f}_{i}^{*}$ & $\tilde{f}_{\bar{i}}^{*}$ \\
\hline Thermal Conductivity & 0.141 & 0.057 & 0.557 & 0.225 \\
\hline Density & 0.003 & 0.023 & 0.086 & 0.615 \\
\hline Specific Heat & 0.040 & 0.005 & 0.864 & 0.115 \\
\hline Melting Point & 0.021 & 0.004 & 0.786 & 0.155 \\
\hline Latent Heat of Fusion & 0.050 & 0.008 & 0.707 & 0.121 \\
\hline Thermal Expansion & 0.017 & 0.090 & 0.116 & 0.608 \\
\hline Cost / kg & 0.018 & 0.409 & 0.044 & 0.985 \\
\hline
\end{tabular}

Table 8: TOPSIS AND VIKOR Computation

\begin{tabular}{|c|c|c|c|c|r|r|r|r|}
\hline & \multicolumn{4}{|c|}{ TOPSIS } & \multicolumn{4}{|c|}{ VIKOR } \\
\hline Alternatives & $\mathbf{D j}^{*}$ & $\mathbf{D j}-$ & $\mathbf{C} \mathbf{C}_{j}^{*}$ & \multicolumn{1}{|c|}{ Rank } & \multicolumn{1}{l|}{$S_{i}$} & \multicolumn{1}{l|}{$R_{i}$} & \multicolumn{1}{l|}{$Q_{i}$} & Rank \\
\hline Aluminum & 0.098 & 0.414 & 0.807 & 4 & 0.368 & 0.192 & 0.260 & 4 \\
\hline Copper & 0.063 & 0.417 & 0.867 & 1 & 0.240 & 0.102 & 0 & 1 \\
\hline Gold & 0.417 & 0.059 & 0.124 & 6 & 0.781 & 0.415 & 1 & 6 \\
\hline Silver & 0.104 & 0.350 & 0.770 & 5 & 0.335 & 0.116 & 0.110 & 2 \\
\hline Tungsten & 0.096 & 0.413 & 0.810 & 3 & 0.384 & 0.253 & 0.373 & 5 \\
\hline Zirconium & 0.070 & 0.403 & 0.852 & 2 & 0.293 & 0.176 & 0.167 & 3 \\
\hline
\end{tabular}




\section{Results and Discussion}

The results of the proposed methodology are given in Table 9. The results of the TOPSIS and VIKOR methodologies for selecting the suitable heat sink material for electronic manufacturing industry are described next. The ranking order from TOPSIS is based on closeness coefficient (Copper $=0.867>$ Zirconium $=0.852>$ Tungsten $=0.810>$ Aluminum $=0.807>$ Silver $=0.770>$ Gold $=0.124)$. The ranking order of materials obtained from VIKOR is based on VIKOR index (Copper $=0$ $>$ Silver $=0.110>$ Zirconium $=0.167>$ Aluminum $=0.260>$ Tungsten $=0.373>$ Gold $=1$ ). In VIKOR the aggregate functions are always closest to ideal values. In TOPSIS, the closeness coefficients of materials are nearly closest to ideal solution.

Table 9: Result of Proposed Methodologies

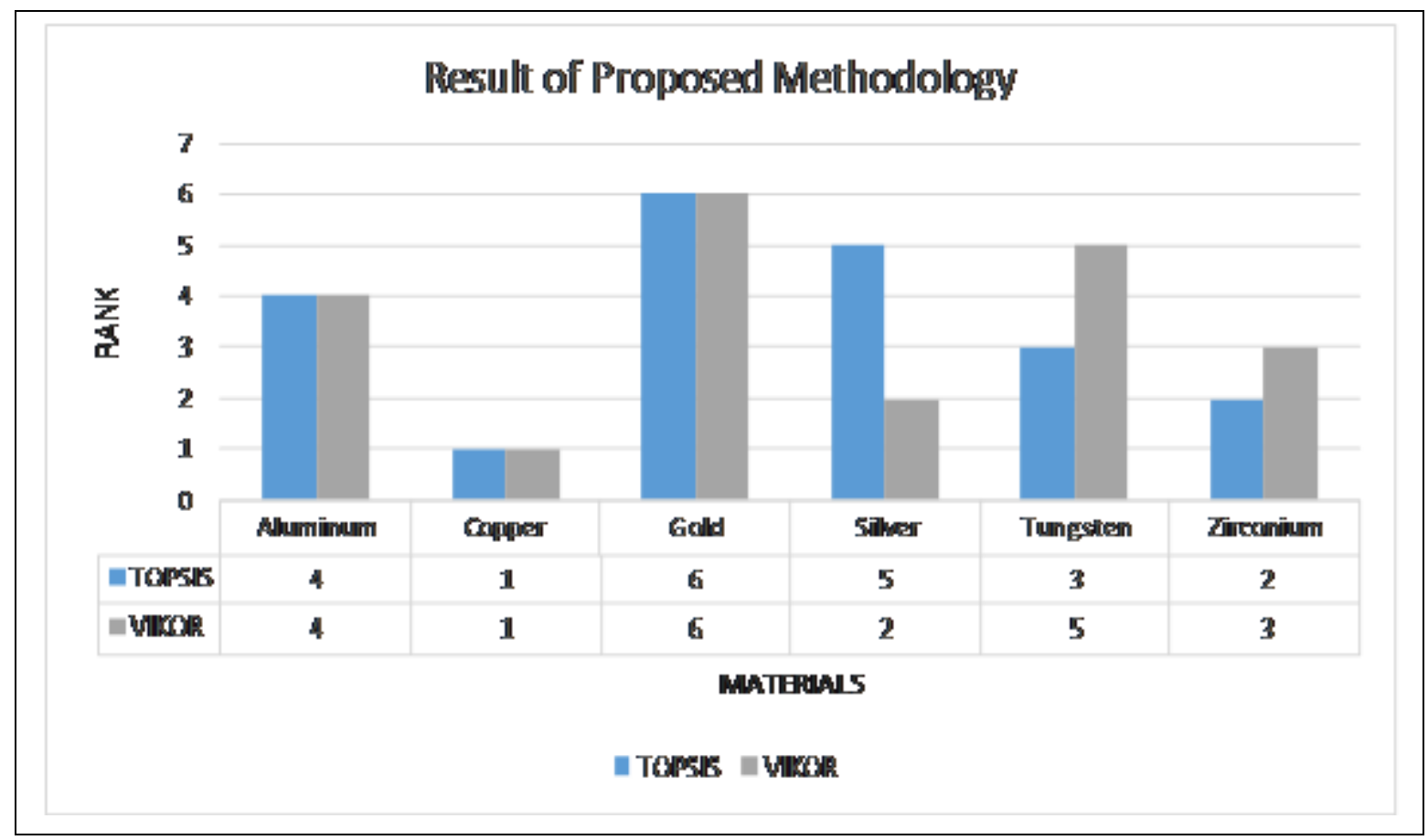

The comparative analysis of these methods shows that VIKOR method had less number of comparisons and valuations. The VIKOR method focuses on ranking and selecting from a set of alternatives in the presence of conflicting criteria. The VIKOR stood out to be the best in reducing computation time and providing desirable result, which was due to elegant method and ease of elegant method and computational easiness. The comparative results show usefulness of VIKOR in providing valuable assistance for material selection.

\section{Conclusions}

Material selection is becoming more and more important because of the failure rates of electronic equipment proliferate exponentially with an increase in temperature. In the present study shows that the fuzzy based multi criteria decision making methodology makes copper material as an appropriate option for manufacturing heat sink materials for electronic cooling applications. The fetched theoretical results proves that the material is much appropriate for manufacturing industry as it is easily available, low cost and high thermal conductivity for particular applications. The results obtained from other integrated techniques will help the designer better understand the criteria involved in the heat sink material selection process. The concepts of fuzzy set theory and hierarchical decision making framework structure analysis are used to develop a weighted suitability decision matrix to evaluate the weighted suitability of different alternatives versus various criteria.

\section{Acknowledgement}

This research is financially supported by FIST (Fund for improvement of science and technology infrastructure) programme by the Department of Science and Technology (DST) New Delhi. DST-FIST (SR/FST/College-235/2014 dated 21-11-2014) and K S Rangasamy College of Technology, Tiruchengode, India.

\section{References}

1. Weilin Qu, Issam Mudawar, Experimental and numerical study of pressure drop and heat transfer in a single-phase micro-channel heat sink (26 October 2001).

2. Prasenjit Chatterjee, Vijay Manikrao Athawale, Shankar Chakraborty, Selection of industrial robots using compromise ranking and outranking methods (30 March 2010). 
3. Ed Walsh, Pat Walsh, Ronan Grimes, Vanessa Egan, Thermal Management of Low Profile Electronic Equipment Using Radial Fans and Heat Sinks.

4. Xifeng Zhao, Jinju Sun, Chao Wang, Zhi Zhang b Experimental and numerical study of electronic module-cooling heat sinks used in a variable frequency air-conditioner outdoor unit (16 October 2013).

5. Ravi Kandasamy, Xiang-Qi Wang, Arun S. Mujumdar, Transient cooling of electronics using phase change material (PCM)-based heat sinks (24 June 2007).

6. M.K. Rathod, H.V. Kanzaria, A methodological concept for phase change material selection based on multiple criteria decision analysis with and without fuzzy environment, Materials \& Design, 32 (2011) 3578-3585.

7. X.-Q. Wang, C. Yap, A.S. Mujumdar, A parametric study of phase change material (PCM)-based heat sinks, International Journal of Thermal Sciences, 47 (2008) 1055-1068.

8. R. Baby, C. Balaji, Experimental investigations on thermal performance enhancement and effect of orientation on porous matrix filled PCM based heat sink, International Communications in Heat and Mass Transfer, 46 (2013) 27-30.

9. Eric Afful-Dadzie, Zuzana Komínková Oplatková, Luis Antonio Beltran Prieto Comparative State-of-the-Art Survey of Classical Fuzzy Set and Intuitionistic Fuzzy Sets in Multi-Criteria Decision Making (18 July 2016)

10. S. Opricovic, G.H. Tzeng, Compromise solution by MCDM methods: a comparative analysis of VIKOR and TOPSIS, Eur. J. Oper. Res. 156 (2004) 445-455.

11. M. Dagdeviren, S. Yavuz, N. Kilinc, Weapon selection using the AHP and TOPSIS methods under fuzzy environment, Expert Syst. Appl. 36 (2009) 8143-8151.

12. C.C. Sun, A performance evaluation model by integrating Fuzzy AHP and fuzzy TOPSIS methods, Expert Syst. Appl. 37 (2010) 7745-7754.

13. M.-T. Chu, J. Shyu, G.-H. Tzeng, R. Khosla, Comparison among three analytical methods for knowledge communities group-decision analysis, Expert Systems with Applications, 33 (2007) 1011-1024.

14. Sen Liu ${ }^{a}$, Felix T.S. Chan ${ }^{b,}$, Wenxue Ran ${ }^{a}$,'Decision making for the selection of cloud vendor: An improved approach under group decision-making with integrated weights and objective/subjective attributes ( 9 February 2016)

15. R.V. Rao, A decision making methodology for material selection using an improved compromise ranking method, Materials \& Design, 29 (2008) 1949-1954.

16. M.-J.J. Wang, C. Tien-Chien, Tool steel materials selection under fuzzy environment, Fuzzy Sets and Systems, 72 (1995) 263-270.

17. T.L. Satty, The analytic hierarchy process, in, New York: McGraw-Hill New York, 1980.

18. M. KHAJEH, Water conservation in Kuwait: a fuzzy analysis approach, Journal of Industrial Engineering International, (2010).

19. P.J.M. van Laarhoven, W. Pedrycz, A fuzzy extension of Saaty's priority theory, Fuzzy Sets and Systems, 11 (1983) 199-227

20. C.L. Hwang, K. Yoon, Multiple Attribute Decision Making: Methods and Applications. New York: Springer. (1981).

21. A. Shanian, O. Savadogo, TOPSIS multiple-criteria decision support analysis for material selection of metallic bipolar plates for polymer electrolyte fuel cell, Journal of Power Sources, 159 (2006) 1095-1104.

22. L.A. Zadeh, Fuzzy sets, Information and control, 8 (1965) 338-353

23. R.E. Bellman, L.A. Zadeh, Decision-making in a fuzzy environment, Management science, 17 (1970) B-141-B-164

24. O. Kulak, M.B. Durmuşoğlu, C. Kahraman, Fuzzy multi-attribute equipment selection based on information axiom, Journal of Materials Processing Technology, 169 (2005) 337-345.

25. G. Büyüközkan, C. Kahraman, D. Ruan, A fuzzy multi-criteria decision approach for software development strategy selection, International Journal of General Systems, 33 (2004) 259-280.

26. M. Ilangkumaran, $P$. Thamizhselvan, Integrated hazard and operability study using fuzzy linguistics approach in petrochemical industry, International Journal of Quality \& Reliability Management, 27 (2010) 541-557.

27. C.-H. Yeh, Y.-H. Chang, Modeling subjective evaluation for fuzzy group multicriteria decision making, European Journal of Operational Research, 194 (2009) 464-473.

28. T.-C. Wang, T.-H. Chang, Application of TOPSIS in evaluating initial training aircraft under a fuzzy environment, Expert Systems with Applications, 33 (2007) 870-880.

\section{Author' biography with Photo}

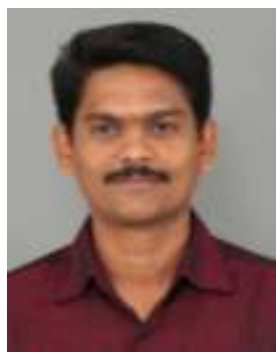

L.Arulmurugan was born in India in 1983. He is presently working as Assistant Professor(SG), Department of Mechatronics Engineering, K S Rangasamy College of Technology, Tiruchengode, India. He is pursuing his Ph.D in the faculty of information and communication engineering from Anna University Chennai and he holds a ME degree in Applied Electronics from Anna university, Chennai. and BE in Electronics and Communication Engineering from Bharathiar University, Coimbatore. He has published two international journals and four papers in international and national conferences. He is a life member of ISTE. His research interest is Electronics cooling system and Decision Support System. 
Dr. M. Ilangkumaran was born in India in 1978. Professor and Head, Department of Mechatronics Engineering, K.S.Rangasamy College of Technology, Tiruchengode, India. He completed his graduation in Mechanical Engineering from K.S.Rangasamy College of Technology, Tiruchengode in 1999 and Masters in Industrial Engineering from Kumaraguru College of Technology, Coimbatore in 2001. He received his Ph.D in maintenance management from Anna University in 2010. He is currently working as Professor and Head, Mechatronics Engineering, K.S.Rangasamy College of Technology, Tiruchengode, India. His research interest is optimization in IC engines and maintenance management. He has published more than Forty three international and national journals and he presented six papers in national conferences. He is a life member of ISTE. 